\title{
Ways of increasing excavator fleet productivity in Russian coal open pits (Kuzbass case study)
}

\author{
Michael Drygin ${ }^{1, *}$, Nicholas Kurychkin ${ }^{1}$ and Alexander Bakanov ${ }^{1}$ \\ ${ }^{1}$ T. F. Gorbachev Kuzbass State Technical University, 28 Vesennyaya str., Kemerovo 650000, Russia
}

\begin{abstract}
A steady increase in coal extraction in Russian Federation and worldwide results from objective causes of natural resources availability and development of advanced coal processing technologies. In the context of the long-standing economic crisis, considerable investments in coal industry are not to be expected. Consequently, the reserve for extraction growth lies in increasing productivity of the key equipment applied in Kuzbass coal pits. The production data analysis revealed that the presented excavators working capacity does not depend on the bucket volume and the cycle time. It is hereby specified that working capacity is primarily dependent on the actual operation cycle time. As it is demonstrated, the key reserve for increasing the working capacity consists in elevating efficiency of actual performance time use.
\end{abstract}

\section{Introduction}

Significant volumes of coal resources compared to oil and gas resources place the world coal industry in top position in the world fuel and energy sector structure. Similar processes are ongoing in such countries as the USA, China, India, RSA and Australia. The coal industry development is the basis of their economic, technological and environmental policy. The economy orientation to implementing advanced coal processing technologies plays quite a significant (if not the principal) role in the coal industry development. Production of coking coal, sorbents, resins, benzene, methanol, carbon fiber, fertilizers and electric power (on production site) also places the coal industry among the leaders in the Russian economic development.

Kemerovo region is the leading coal region in Russia. 75\% of all the Russian coal volumes and $2 / 3$ of all the coking coal volumes are extracted here. The prospective objective is to set up new mines and pits in Kuzbass with overall annual capacity of over 50 mln tonnes of coal by 2030. Therefore, the tendencies and particularities of the Kuzbass coal mining industry fully reflect the tendencies and particularities of the Russian Federation coal industry.

Over $70 \%$ of coal in Kuzbass is extracted by open pit mining. This method possesses apparent advantages compared to underground mining and is characterized by higher productivity, low production cost and safe mining operations.

\footnotetext{
*Corresponding author: mike.drygin@gmail.com
} 
The prospect of consistent increase in open pit coal extraction in the years to come has to be ensured not only by commissioning new facilities but also by increase in labour productivity and consequently by reduction of coal production cost [1]. This result can be achieved in two ways: firstly, by considerable investments in purchase of modern equipment (excavators, bulldozers, mine trucks) and secondly, by reducing idle time periods of the principal mining equipment [2] due to implementation of new advanced methods of the equipment operation and repair organization [3].

The first way is unlikely to be considered as feasible in the context of the long-standing economic crisis and of chronical funds shortage. Fig. 1 shows excavator commissioning / decommissioning trends within the largest Kuzbass coal company UK Kuzbassrazrezugol from 2008 till 2015.

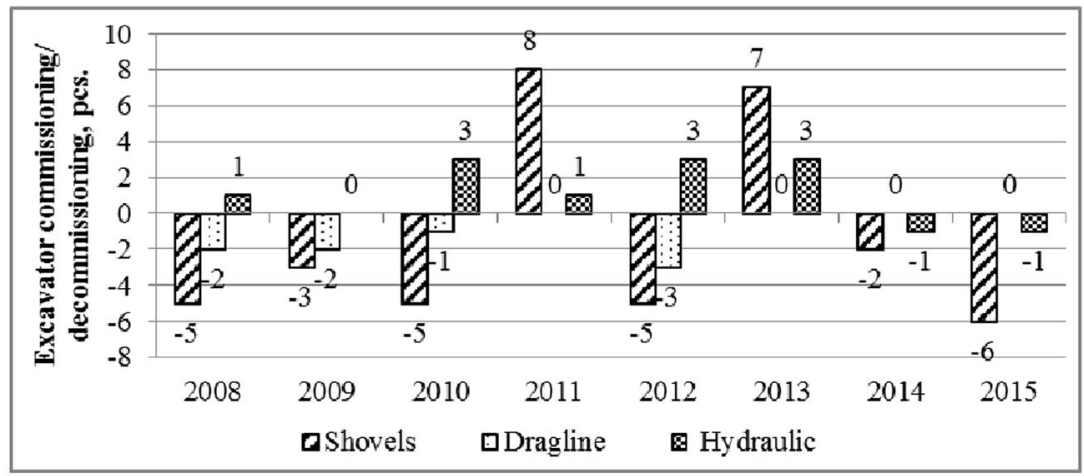

Fig. 1. Excavator commissioning / decommissioning trends in UK Kuzbassrazrezugol

As shown on the diagram, the trends of quality and quantity alterations of the excavator fleet are disappointing. During the 8 year period till 2015, the total of 34 excavators have been decommissioned and only 26 new equipment units have been purchased. With this, decommissioning and putting new equipment in operation is sporadic, with exception of years 2011-2013 when mass commissioning of imported and Russian shovel excavators took place. In recent years the systematic policy of expanding the fleet with single excavator units of high capacity is being implemented. However, despite this policy the mentioned units do not play a significant part in excavation volumes. According to the UK Kuzbassrazrezugol data, only $12 \%$ of overburden was moved in 2015 by the new excavators made in Russia with the bucket volume exceeding $10 \mathrm{~m}^{3}$, whereas $23 \%$ was moved by the new imported electric units.

The second way is the most feasible one for the present time. The key parameter which characterizes open pit mining efficiency is the working capacity of principal open pit production equipment, that is of various types of excavators.

\section{Results and discussion}

The major factors affecting the excavator productivity include:

- difficulty of overburden excavation which depends on the rock type and state and which affects the bucket filling up coefficient [4];

- the excavator technical condition and reliability [4];

- the operator's qualifications [5];

- the face quality estimated by its bench height, truck access to the loading point, illumination [6]; 
- operations management determined by sufficient fleet size, roadways condition, timely supply of fuel, power, spare parts [7; 3].

Excavator productive capacity includes theoretical (rated), technical and working capacity.

Theoretical productive capacity per hour of continuous operation is calculated by the following formula:

$$
P_{d}=60 \mathrm{gn},
$$

where $g$ is geometrical bucket capacity in $\mathrm{m}^{3}$ and $n$ is number of cycles per minute.

The number of cycles per minute depends on the length of one cycle:

$$
n=60 /\left(t_{d}+t_{s}+t_{d u}+t_{s b}\right) \text {, }
$$

where $t_{d}$ is digging time, $10-20 \mathrm{~s}$; $t_{s}$ is swinging time, $4-6 \mathrm{~s} ; t_{d u}$ is dumping time, $3-5 \mathrm{~s} ; t_{s b}$ is swinging back time, 2-3 $\mathrm{s}$ [8].

Working productive capacity is the excavator average actual productivity $\left(\mathrm{m}^{3} / \mathrm{h}\right)$ during operation in specified conditions with account of unavoidable idle time, time losses for shift changeover and equipment inspection, lubrication and rolling stock replacement. The working productive capacity indicator is lower than the technical productive capacity. This indicator shows efficiency of organizing operations of the excavator and all its service equipment:

$$
P_{w}=60 g k_{f} k_{o} n / k_{g},
$$

where $k_{f}$ is the bucket filling up coefficient; $k_{o}$ is the equipment operating time utilization coefficient which represents the ratio between the actual operations time and the total consumed time; $k_{g}$ is the ground swell coefficient. Coefficients which make part of formula (3) are assumed equal to: $k_{f}=(0.8-1.5)$ (depending on ground type, humidity and the operating equipment type $) ; k_{o}=(1.1-1.3) ; k_{s}=(0.75-0.85)$.

Formulas (1), (2), (3) demonstrate that the excavator productive capacity depends above all on the bucket volume $g$ and on the cycle time $[6,9]$. In reality this is revealed in the following way. Fig. 2 presents the year-to-year relationship between the overall bucket volume $\left(\mathrm{m}^{3}\right)$ of all the excavators operating in UK Kuzbassrazrezugol (KRU) open pits and their aggregate working productive capacity ( $\mathrm{mln} \mathrm{m}^{3} /$ year).

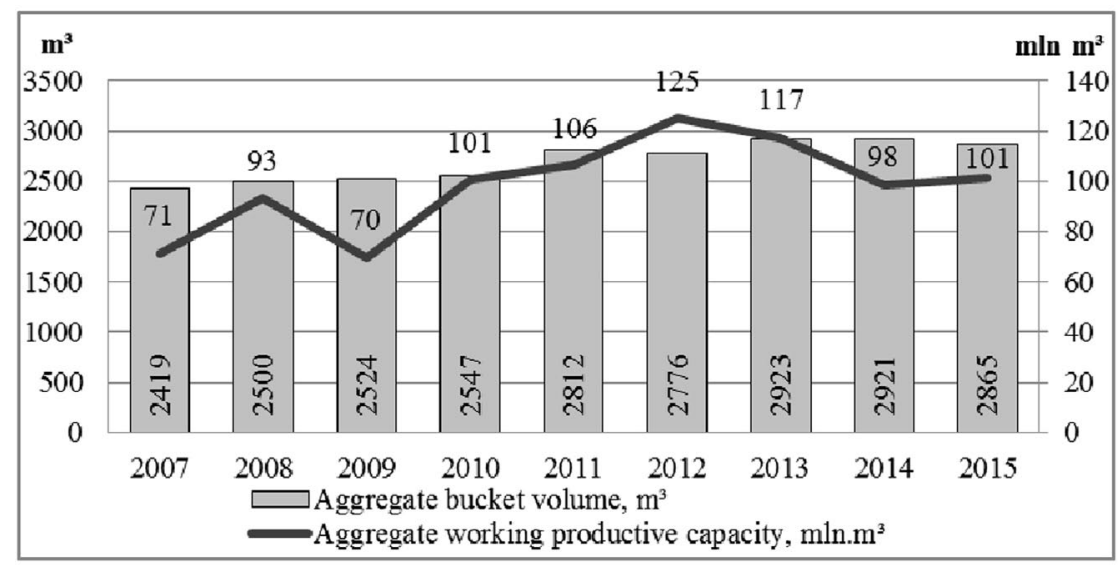

Fig. 2. Aggregate bucket volume and aggregate working productive excavators' capacity in UK KRU 
The diagram shows that these indicators have no correlation from year to year. Thus, from 2012 to 2013 the aggregate bucket volume has increased by 5\%, whereas the aggregate productive capacity on the contrary has decreased by $6.2 \%$. Comparing years 2014 and 2016 , the contrary situation is observed: with decrease in the aggregate volume by $2 \%$ the aggregate working productive capacity increased by $3.2 \%$. However, the general tendency of both indicators improvement during 9 years from 2007 to 2015 remains unchanged with the increase in overall bucket volume by $15.6 \%$ the aggregate working productive capacity increased by $29.7 \%$.

Therefore, analysis of the Fig. 2 diagram shows that the excavator working productivity is in minor dependence on its bucket volume [10]. This conclusion is confirmed by analyzing another diagram (Fig. 3).

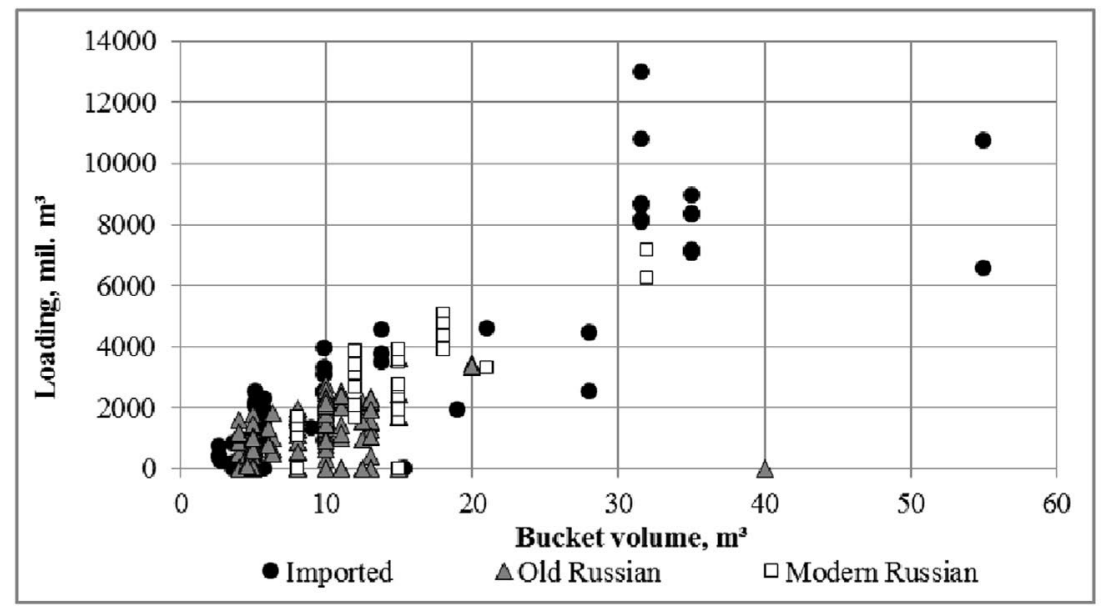

Fig. 3. Relation between the overburden loading volume in 2015 and the bucket volume of excavators in UK Kuzbassrazrezugol

The dot diagram shows that, for instance, in 2015 one of the two imported excavators with bucket volumes of $28 \mathrm{~m}^{3}$ each has moved twice as much overburden as the second one. Excavators with bucket volumes of $32 \mathrm{~m}^{3}$ have an annual loading volume variation exceeding $100 \%$. But two imported excavators with bucket volumes of $55 \mathrm{~m}^{3}$ each have moved less overburden for the year than two excavators with bucket volumes of $32 \mathrm{~m}^{3}$.

Examining the influence of the cycle time and wear rate of different types of excavators on working productivity in actual conditions; Fig. 4 demonstrates the diagram of specific productive capacity (working capacity per $1 \mathrm{~m}^{3}$ of bucket volume) for various types of excavators as well as diagrams of equipment wear rate depending on time and performed operation volumes. It is apparent that due to constructive particularities of various excavator types the cycle time of their operation differs $[7,11]$.

Analysis of the diagrams shows that the specific productive capacity variation for various types of excavators is not significant. The same conclusion can be made for the influence of the excavator wear rate on specific productive capacity. As shown on the diagram, excavators with the wear rate exceeding 100\% (EKG-10, EKG-15, ESh-10/70) have the same specific productive capacity as the new excavators with the wear rate of $(10-15) \%$ (EKG-18P, EKG-32, P\&H-4100XPC, WK-35). 


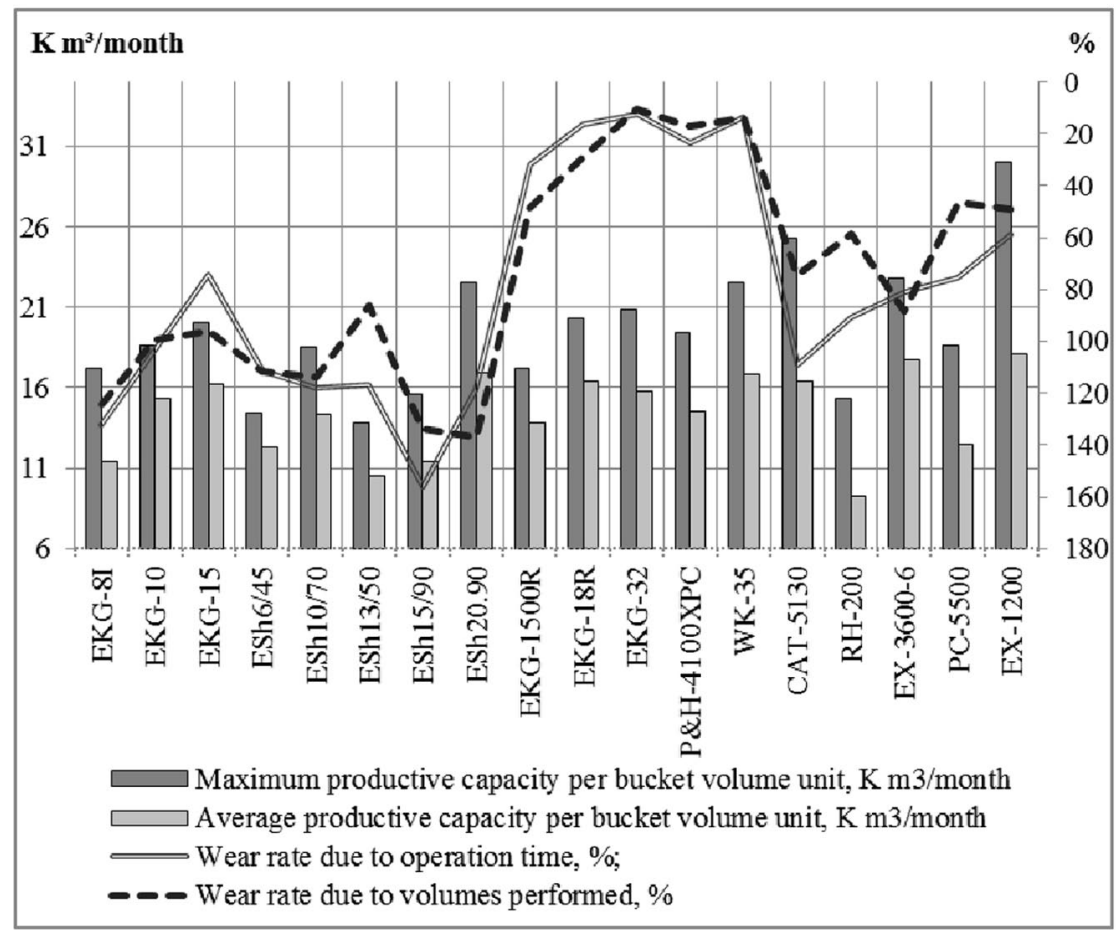

Fig. 4. Specific productive capacity of excavators in UK Kuzbassrazrezugol open pits.

The diagram drawn for dragline ESh 10/70 is illustrative (Fig. 5). The diagram shows that during four years from 2012 to 2015 the working productive capacity of this excavator has steadily been lower than its theoretical productive capacity by 2.5 times on average. However, after the excavator upgrade in the end of 2015, including replacement of the 10 $\mathrm{m}^{3}$ bucket by a $13 \mathrm{~m}^{3}$ one and decreasing the boom length to $50 \mathrm{~m}$, the theoretical productive capacity has increased by $75 \%$. On the other hand, the working productive capacity has remained at the same level.

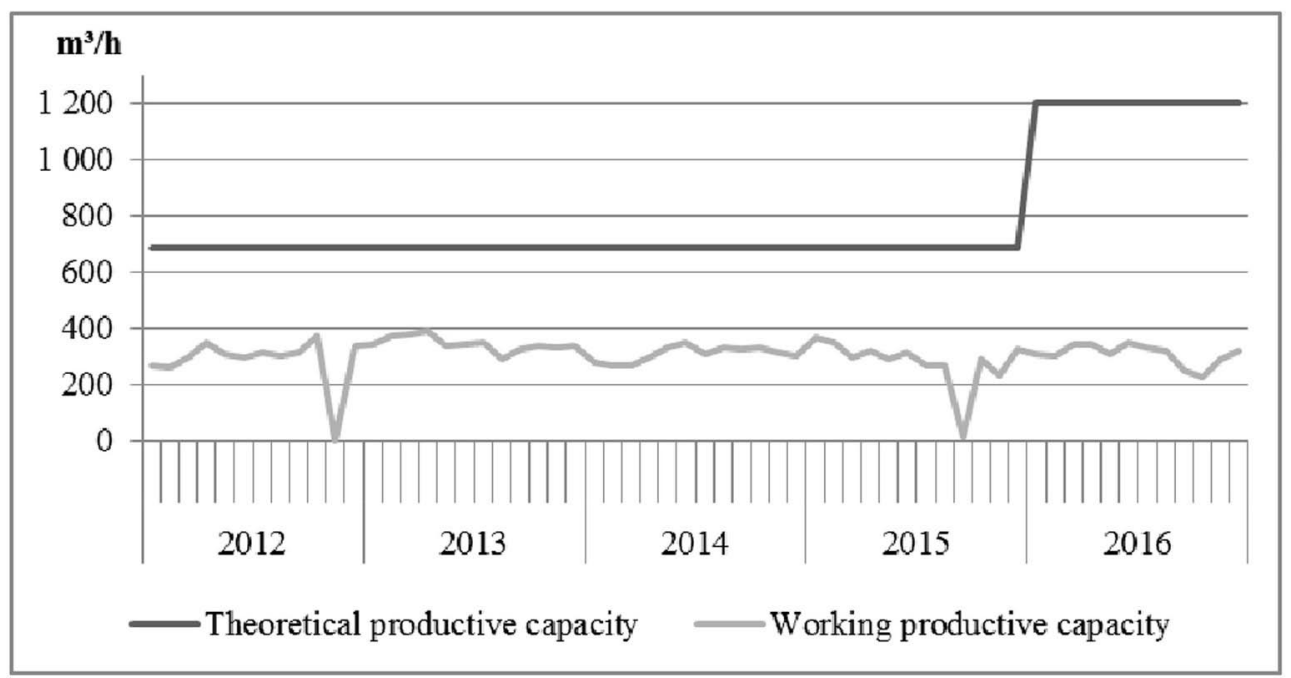

Fig. 5. Theoretical and working productive capacity of ESh-10/70 excavator. 
Analyzing the obtained result it can be concluded that after commissioning of new excavators with improved principal operational parameters the overall fleet productive capacity had a lower increase than was expected. Meanwhile, the actual working productive capacity of particular equipment units with similar parameters differs considerably.

Therefore it can be assumed that this result is caused by considerable increase in various scheduled and unplanned idle times [12;13].

Yet, the below diagram refutes this thesis as well. Fig. 6 demonstrates year-to-year alteration of various idle time percentages of UK Kuzbassrazrezugol excavators for years 2007-2015. The diagram shows that the idle time periods caused by planned repair and technological pauses in operation have the maximum specific percentage in the idle time structure $[14,15]$, amounting to an average of $14 \%$ and $10 \%$ from overall working time fund respectively.

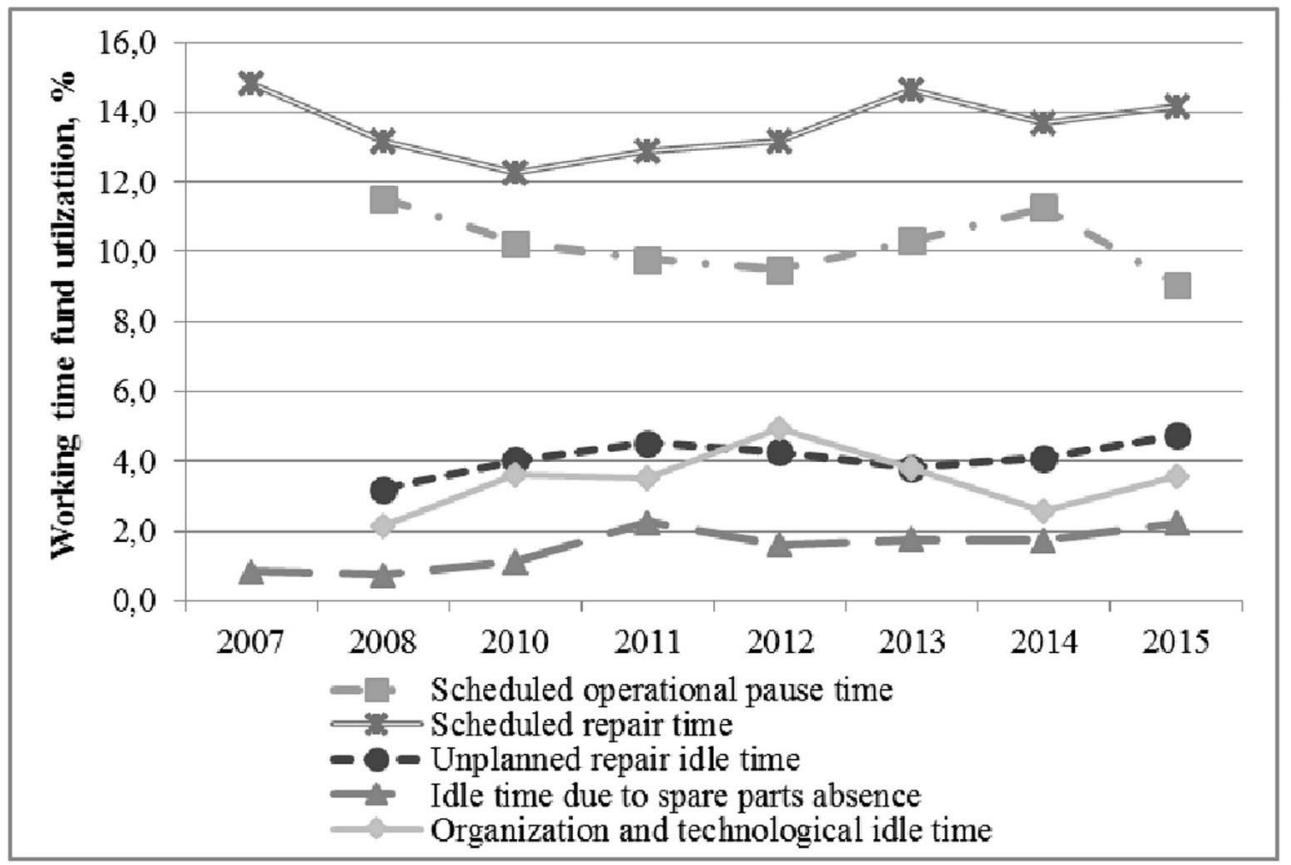

Fig. 6. Trends of working time fund utilization of excavator fleet in UK Kuzbassrazrezugol open pits by years.

However during eight years these indicators have decreased by $5 \%$ and $22 \%$. Other types of idle time related to unplanned repair, absence of spare parts and organization and technological events amount to in total to (8-9)\% of the working time fund. Their insignificant increase is offset by a decrease in idle time related to scheduled repair and operational pause time. Consequently, no increase in scheduled as well as unplanned idle time is observed.

Therefore, the production data analysis at Kuzbass open pits has revealed that excavator specific working productivity does not depend on the theoretical operation cycle time; moreover, the actual productivity does not depend on equipment wear rate based on operation time and volumes performed.

\section{Conclusion}

The studies performed made it possible to draw the following conclusions: 
1. A steady increase in coal extraction in Russian Federation and worldwide results from objective causes of natural resources availability and development of advanced coal processing technologies.

2. In the context of the long-standing economic crisis and chronical funds deficiency, investments in Russian coal industry are not substantial. Consequently, the tendency of excavator fleet renewal in coal pits is poor, whereas newly commissioned excavators play no significant part in the coal extraction volume increase.

3. One of the principal indicators characterizing the excavator operating efficiency is its specific working productivity which does not depend on the theoretical operational cycle time.

4. The actual working capacity of Kuzbass open pit excavators does not depend on equipment wear rate based on operation time and volumes performed.

5. It was established that the working productive capacity is in primary dependence on the actual operational cycle time. As shown hereby, the principal reserve of the working productive capacity increase lies in elevating efficiency of actual performance time use.

\section{References}

1. H. Aykul, E. Yalcin, I.G. Ediz, D.W. Dixon-Hardy and H. Akcakoca, The Journal of The Southern African Institute of Mining and Metallurgy, 107 (2007)

2. V. M. Kalra, T. Thakur, B.S. Pabla, IOSR J. of Mech. and Civil Engineering (2015)

3. P. Rai, Indian Journal of Engineering \& Materials Sciences, 11 (2004)

4. C. Kirmanli and S.G. Ercelebi, The Journal of The Southern African Institute of Mining and Metallurgy, 109 (2009)

5. S. Namata, Performance analysis of heavy earth moving machineries (hemm) in opencast coal mines (Department of Mining Engineering, Rourkela National Institute of Technology, 2015)

6. H. Naik, The Indian Mining and Engineering Journal, 13 (2015).

7. R. Andreev, Evaluation of Hydraulic Excavator and Rope Shovel Major Maintenance Costs in Operation (Department of Civil and Environmental Engineering, University of Alberta, 2015)

8. P. Rai, R. Trivedi and R. Nath. Indian J of Eng \& Materials Sciences, 7 (2000)

9. A. Hall, Characterizing the Operation of a Large Hydraulic Excavator (The University of Queensland, Brisbane, Australia, 2002)

10. E. Bozorgebrahimi, R.A. Hall and G.H. Blackwell, Mining Technology, 112 (2003)

11. D. Mahambetov, B. Rakishev, G. Samenov, A. Sładkowski, Trans. Problems, 8 (2013)

12. M.E. Michael Arputharaj, Int. J. of Adv. Res. in Eng. and Tech.(IJARET), 6 (2015)

13. A. Lanke, H. Hoseinie, B. Ghodrati, International Scholarly and Scientific Research \& Innovation, 8 (2014)

14. S. Elevli, B. Elevli, Acta Montanistica Slovaca, 15 (2010)

15. C. Drebenstedt, R. Singhal, Proceedings of the $22^{\text {nd }}$ MPES Conference (Dresden, Germany, 2013) 